\title{
Follicular Lymphoma Presenting With Monoclonal IgM And MYD88 Mutation: A Case Report And Review Of The Literature
}

This article was published in the following Dove Press journal: OncoTargets and Therapy

\section{Linglong $\mathrm{Xu}$ \\ Xiaoxiao Ding \\ Limei Ying \\ Xiaochang Zhang \\ Nina Lu}

Department of Hematology, Taizhou Central Hospital (Taizhou University Hospital), Taizhou, Zhejiang, People's Republic of China
Correspondence: Linglong Xu Department of Hematology, Taizhou Central Hospital (Taizhou University Hospital), 999 Donghai Road, Taizhou, Zhejiang 318000, People's Republic of China

Tel +8657688526258

Email daniongniong@163.com

\begin{abstract}
MYD88 mutation has been reported in various lymphomas, specifically in lymphoplasmacytic lymphoma. Yet, the mutation has not been reported in primary follicular lymphoma. Here, we present a 62-year-old male with follicular lymphoma who had an MYD88 L265P somatic mutation and monoclonal IgM gammopathy. He received four cycles of R-CHOP immunochemotherapy. Interim PET/CT evaluation indicated a state of stable disease (SD). Neither did serum IgM remarkably drop. He was then given a bortezomibcontained regimen which significantly reduced the level of serum IgM. To the best of our knowledge, this is the first report of follicular lymphoma with monoclonal IgM and MYD88 L265P mutation. The present case indicated bortezomib may benefit these patients.
\end{abstract}

Keywords: follicular lymphoma, monoclonal gammopathy, immunochemotherapy, MYD88 mutation

\section{Introduction}

Follicular lymphoma (FL) is an indolent lymphoproliferative disorder of B-cells with variable clinical behavior, as the second most common subtype of nonHodgkin lymphoma in western countries, and its incidence accounts for $3.2-7.0 \%$ of non-Hodgkin lymphoma in China. ${ }^{1-3}$ The main morphological feature of FL is a proliferation of neoplastic germinal center (GC) B cells, both centrocytes and centroblasts, with at least a partial follicular pattern. ${ }^{4}$ It has been reported that $\mathrm{t}$ $(14 ; 18)(\mathrm{q} 32 ; \mathrm{q} 21)$ translocation exists in the majority of FL patients, resulting in an overexpression of Bcl-2 protein. Due to the heterogeneity and incurability of FL, the presence of symptoms, the tumor burden, the patient's age, and comorbidities, and the therapeutic targets need to be taken into account, when an FL patient is managed. 4

MYD88 is an important adaptor protein in the nuclear factor- $\kappa \mathrm{B}(\mathrm{NF}-\kappa \mathrm{B})$ and mitogen-activated protein kinases (MAPK) signaling pathways, that is involved in multiple biological activities, such as cell survival, proliferation, immune regulation, and tumorigenesis. The somatic mutation of MYD88 has been reported in different types of hematological malignancies, typically in lymphoplasmacytic lymphoma (LPL). ${ }^{5-7}$ However, the mutation has not been reported in primary FL. In this report, we described a newly diagnosed FL patient with MYD88 L265P mutation and immunoglobulin (Ig) M monoclonal gammopathy. We found that the patient poorly responded to immuno-chemotherapy (R-CHOP). 
Written informed consent was provided by the patient to publish the case. The ethics committee of Taizhou Central Hospital approved the publication of the case details.

\section{Materials And Methods Histopathology And Immunohistochemistry}

Lymph node samples were collected and embedded in paraffin. The paraffin sections were histologically and immunohistochemically analyzed. Following immunohistochemical antibodies were applied: CD20 (rabbit monoclonal antibody, Invitrogen), CD79 $\alpha$ (mouse monoclonal antibody, Invitrogen), CD43 (rabbit polyclonal antibody, Invitrogen), CD10 (rabbit polyclonal antibody, Invitrogen), Bcl-2 (rabbit monoclonal antibody, Abcam), CD3 (rabbit monoclonal antibody, Abcam), CD5 (rabbit monoclonal antibody, Invitrogen), Cycline-D1 (rabbit monoclonal antibody, Abcam), CD23 (rabbit monoclonal antibody, Abcam) and Ki-67 (rabbit monoclonal antibody, Invitrogen).

\section{Flow Cytometry}

After isolated from bone marrow, PBMCs were dark incubated with different antibodies. The majority of the antibodies adapted in flow cytometry analysis included: CD19, CD200, cytoplasmic light chain, CD10, CD20, CD79b, CD22, CD5, CD25, CD103, FMC7, and CD138 (all of the antibodies were purchased from Beckman Coulter). Flow cytometry was conducted on a BC Navios.

\section{Polymerase Chain Reaction}

The DNA were extracted from the bone marrow of the patient. Conventional allele-specific polymerase chain reaction was performed to evaluate MYD88 mutation status, as previously described. ${ }^{8}$ Briefly, 200ng of genomic DNA was amplified. Two primers (forward, 5'-AATGTGTGCCAGGGGTAC TTAG-3'; reverse, 5'-CCTTGTACTTGATGGGGAACG-3') were used to clarify the MYD88 L265P mutation. A previously identified MYD88 L265P mutation biological sample was used as positive control.

\section{Next-Generation Sequencing}

The DNA were extracted from both lymph nodes and bone marrow of the patient. A targeted next-generation sequencing was performed using an Ion Torrent Personal Genome Machine (ThermoFisher Scientific, USA), as previously described. ${ }^{9}$ The targeted gene panel consisted of 27 genes, including MYD88 L265P. Ion Reporter Server System
(ThermoFisher Scientific, USA) and Variant Reporter ${ }^{\circledR}$ Software (ThermoFisher Scientific, USA) were adapted to analyze the data according to the manufacturer's instructions.

\section{Case Report}

A 62-year-old male developed a painless mass under the right jaw in 2017, in which the mass enlarged gradually. He was admitted to a local hospital on July 2017. Positron emission tomography-computed tomography (PET-CT) scan indicated a dubious diagnosis of lymphoma (Figure 1). He then underwent resection of the right submandibular mass. The pathological report of the mass revealed that small atypical lymphocytes diffusely or follicle-like distributed and folliclelike structure accounted for $75 \%$ of the whole tissue. The absolute number of centroblasts was $0-5$ for each highpower field (Figure 5). Immunohistochemistry showed that the tumor cells were positively associated with CD20, CD79 $\alpha$, CD43, CD10, and Bcl-2, and negatively associated with CD3, CD5, and Cycline-D1. In addition, the follicular dendritic cell (FDC) network stained with CD23 showed that 5-10\% of tumor cells were positively associated with Ki-67 (Figure 6). The pathological diagnosis was follicular lymphoma, grade I. The bone marrow aspiration was performed and flow cytometry of the bone marrow revealed B cells with abnormal immunophenotype, which indicated follicular lymphoma invasion to the bone marrow (Figure 2A). Genetic testing revealed a normal karyotype: 46, XY (Figure 2B). ${ }^{14}$ The patient was eventually diagnosed with follicular lymphoma (grade 1, stage IV). Given the repeated unexplained fever and night sweating, he received 4 cycles of modified R-CHOP (rituximab (600 mg d0), cyclophosphamide ( $1.0 \mathrm{~g} \mathrm{~d} 1$ ), pegylated liposomal doxorubicin (20 mg d1), vincristine (4 mg d1), and prednisone (90 mg d1-d5)).

After 4 cycles of modified R-CHOP, his symptoms, e.g. fever and night sweating, disappeared. An interim PET-CT scan suggested response of stable disease. His bone marrow was re-assessed, and flow cytometry revealed a minimal residual disease of abnormal B cells accounting for $1.11 \%$ of all nucleated cells in the bone marrow.

An abnormal elevation of IgM serum concentration was observed both before and after R-CHOP (IgM serum concentration was above $23 \mathrm{~g} / \mathrm{L}$, Figure $3 \mathrm{~A}$ ). The serum immunofixation test was performed, that showed the existence of monoclonal $\operatorname{IgM}$ and lambda light chain in the blood (Figure 4A). An MYD88 L265P somatic mutation of the bone marrow was indicated by polymerase chain reaction (PCR) (Figure 4B). And, the mutation in the bone marrow was confirmed by next-generation sequencing. 

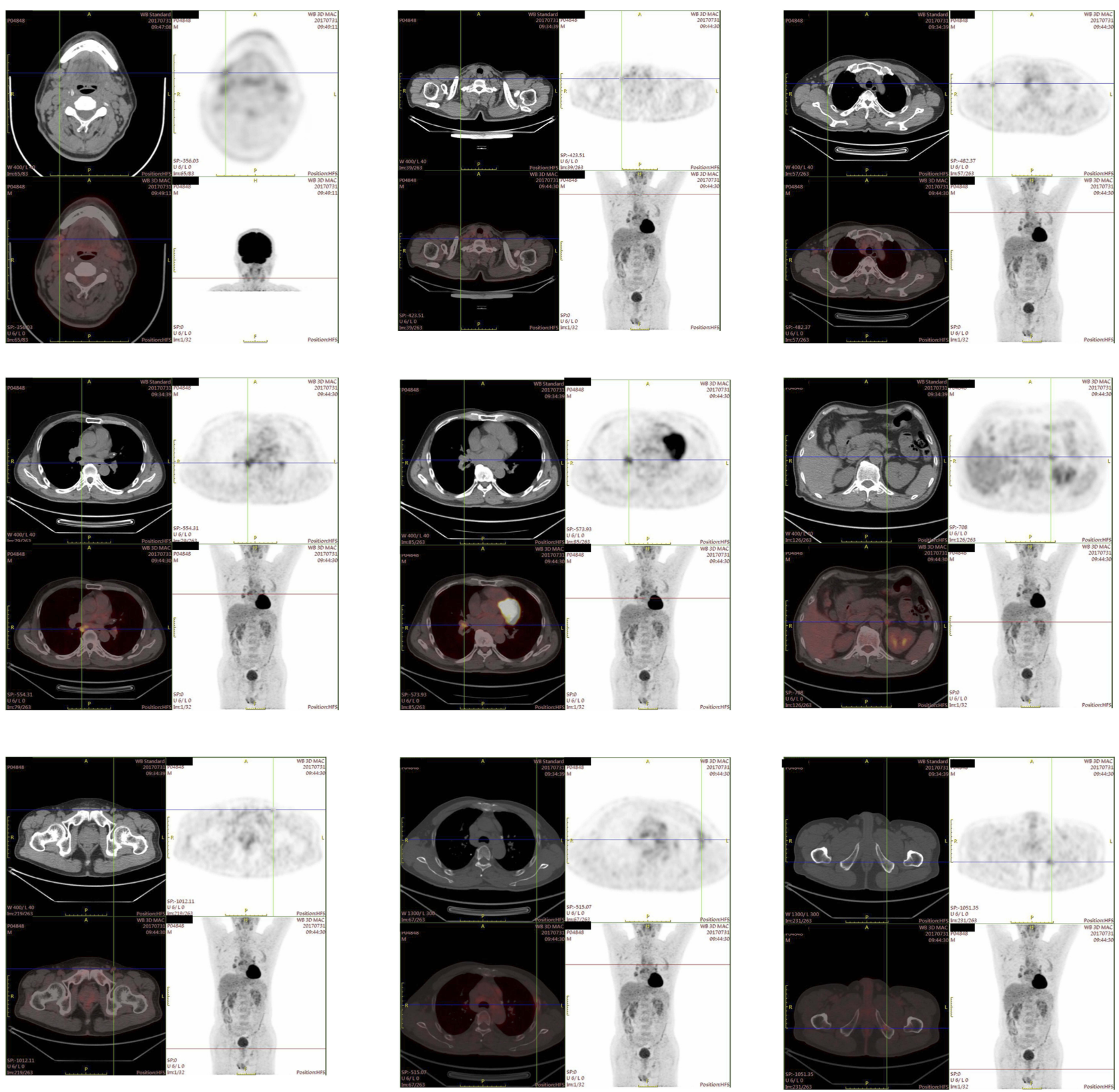

Figure I PET-CT scan (at diagnosis). The PET-CT scan revealed systemic swollen lymph nodes, some of which were FDG-avid. The left ischium had a small high-density area with high FDG-avidity. A diagnosis of lymphoma is suspected.

The mutant allele frequency was $1 \%$. However, no mutation of MYD88 was detected in the sample of the patient's lymph nodes using next-generation sequencing. The original tissue of the patient's lymph node and bone marrow was re-evaluated by a third party pathologist. However, the second pathological diagnosis remained to be follicular lymphoma with bone marrow invasion. An alternative regimen, involving bortezomib (rituximab $(600 \mathrm{mg} \mathrm{d} 1$ ), bortezomib $(2.3 \mathrm{mg} \mathrm{d} 1,8,15)$, dexamethasone $(20 \mathrm{mg} \mathrm{d}$, $8,15)$, which repeated every 28 days, hereafter named R-
$\mathrm{Vd}$ regimen) was presented. After 2 cycles of $\mathrm{R}-\mathrm{Vd}$ regimen, serum IgM concentration significantly decreased (Figure 3B). The patient also received continuous $\mathrm{R}-\mathrm{Vd}$ regimen and waited for another PET-CT scan.

\section{Discussion}

The FL is one of the common B cell lymphomas, originating from cells of germinal centers. The pathological feature of FL is that lymphoma cells evolve in multiple follicle-like structures, containing various centrocytes and centroblasts. In 

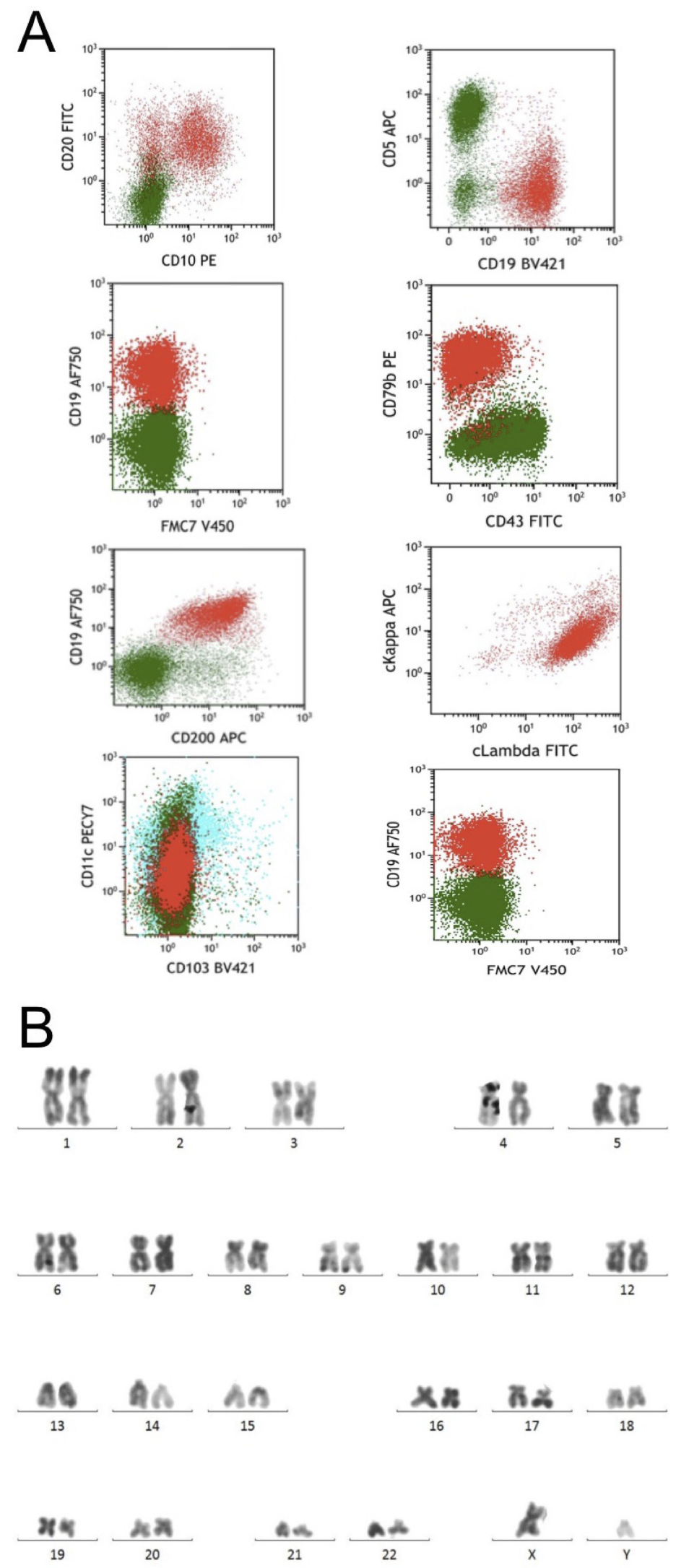

Figure 2 Flow cytometry and cytogenetic results of bone marrow at the time of initial diagnosis. (A) Flow cytometry of bone marrow found B cells with abnormal immunophenotype, which expressed CDI9, CD200, cLambda, CDI0, CD20 and CD79b, not expressing CD5, CDI03 and FMC7. The signals of forward scatter and side scatter indicated a small cell size of the abnormal B cells. (B) R-banding technique revealed a normal karyotype: 46, XY[14]. 


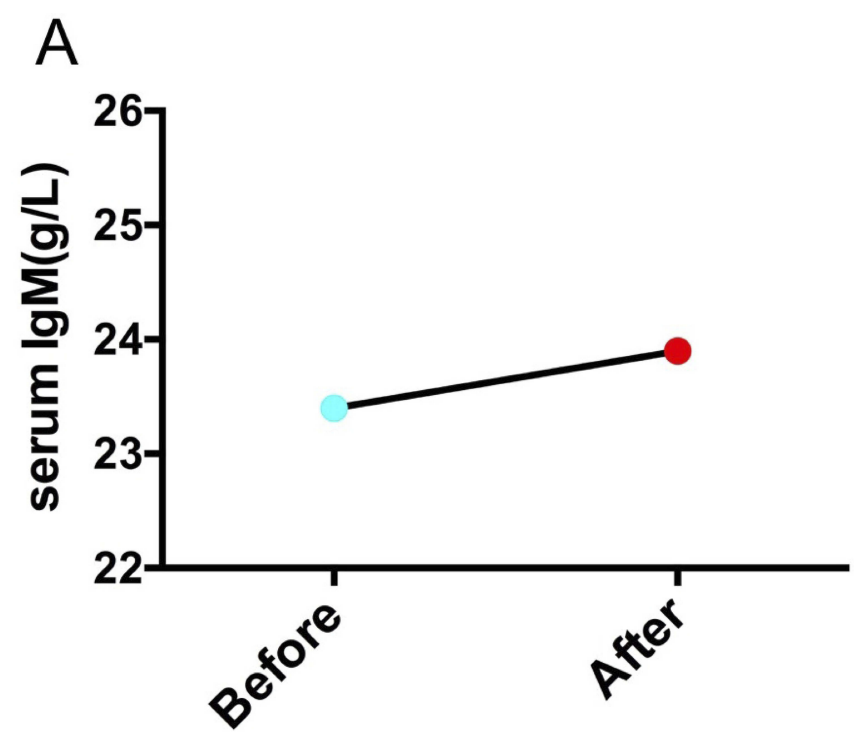

\section{serum IgM before and after $\mathrm{R}-\mathrm{CHOP}$ regimens}

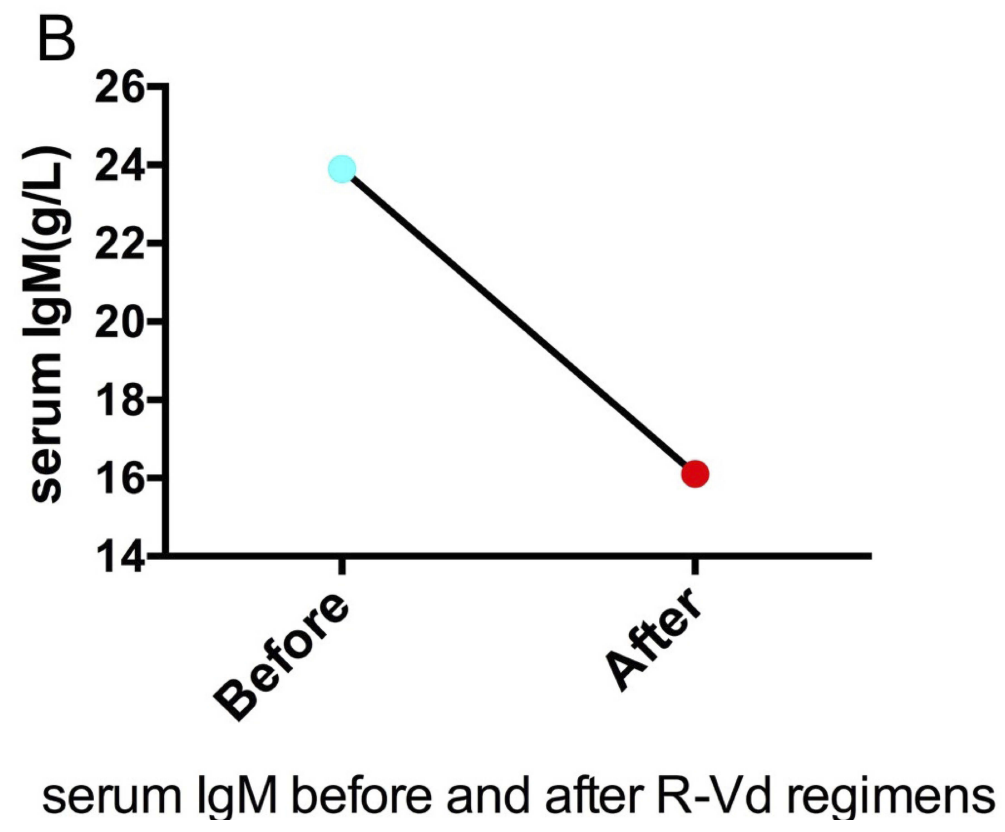

Figure 3 Serum IgM level before and after therapies. (A) The serum IgM level was $23.4 \mathrm{~g} / \mathrm{L}$ before R-CHOP regimen and $23.90 \mathrm{~g} / \mathrm{L}$ after $4 \mathrm{cycles}$ of R-CHOP regimen. (B) The serum IgM level was $23.90 \mathrm{~g} / \mathrm{L}$ before $\mathrm{R}-\mathrm{Vd}$ regimen and $16.10 \mathrm{~g} / \mathrm{L}$ after 2 cycles of R-Vd regimen.

addition, immunohistochemical staining of Bcl-2 showed a positive outcome in the majority of FL cases. Besides, FL cells were positive for $\mathrm{CD} 10$ and negative for $\mathrm{CD} 5$. The mutational landscape of FL was dominated by the $\mathrm{t}(14 ; 18)$ translocation, that was found in $85 \%$ of FL cases, and this translocation places the BCL2 gene under IgH regulatory elements. ${ }^{4}$ The patient in our report underwent PET-CT scan, in which multiple lymph nodes were revealed. A diagnosis of lymphoma is suspected due to the high FDG-avidity of lymph nodes. The biopsy of the right submandibular mass revealed that small atypical lymphocytes were diffusely or follicle-like distributed. Further immunohistochemical staining showed that the immunophenotype of the small atypical lymphocytes met the criteria related to FL. An infiltration of the lymphoma cells in bone marrow was confirmed by a bone marrow aspiration. As a result, the patient was diagnosed with FL stage IV with 

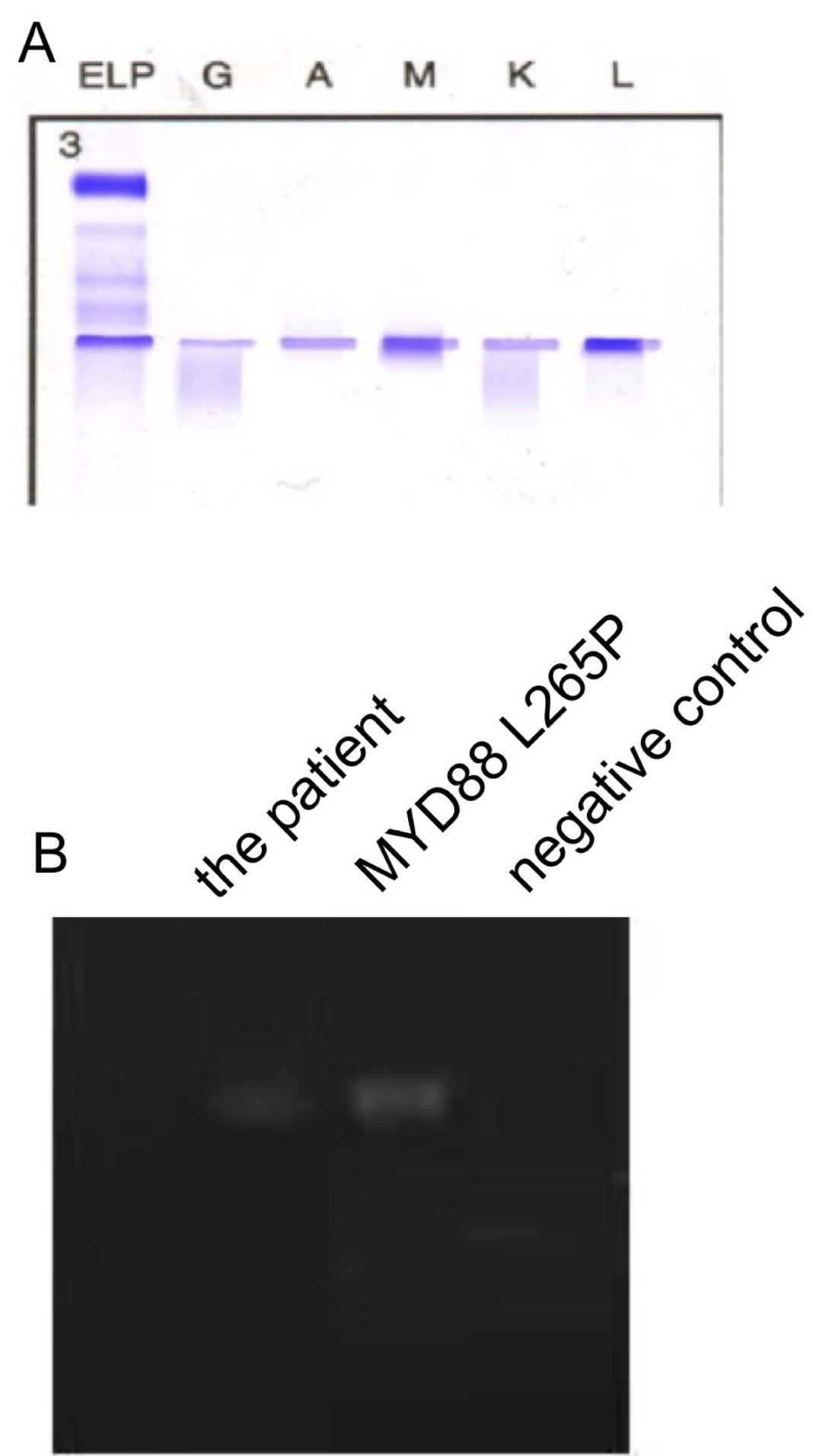

Figure 4 Immunofixation of peripheral blood and MYD88 L265P mutation status of bone marrow. (A) An immunofixation of peripheral blood confirmed the existence of monoclonal IgM and lambda light chain in the blood. (B) A MYD88 L265P somatic mutation was confirmed by a conventional allele-specific polymerase chain reaction. The left lane showed the patient's sample, the middle lane positive control sample, and the right lane negative control sample.

consideration of the pathological report, PET-CT, and bone marrow aspiration.

MYD88 is one of the most important regulatory molecules of pathogen-associated molecular pattern (PAMP) signaling pathway, and it was originally found in the differentiation of myeloid cells. When its upstream Toll-like receptor 4 (TLR4) is combined with PAMP, MYD88 starts to recruit interleukin-1 receptor (IL-1R) associated kinases (IRAK), activating NF-kB 

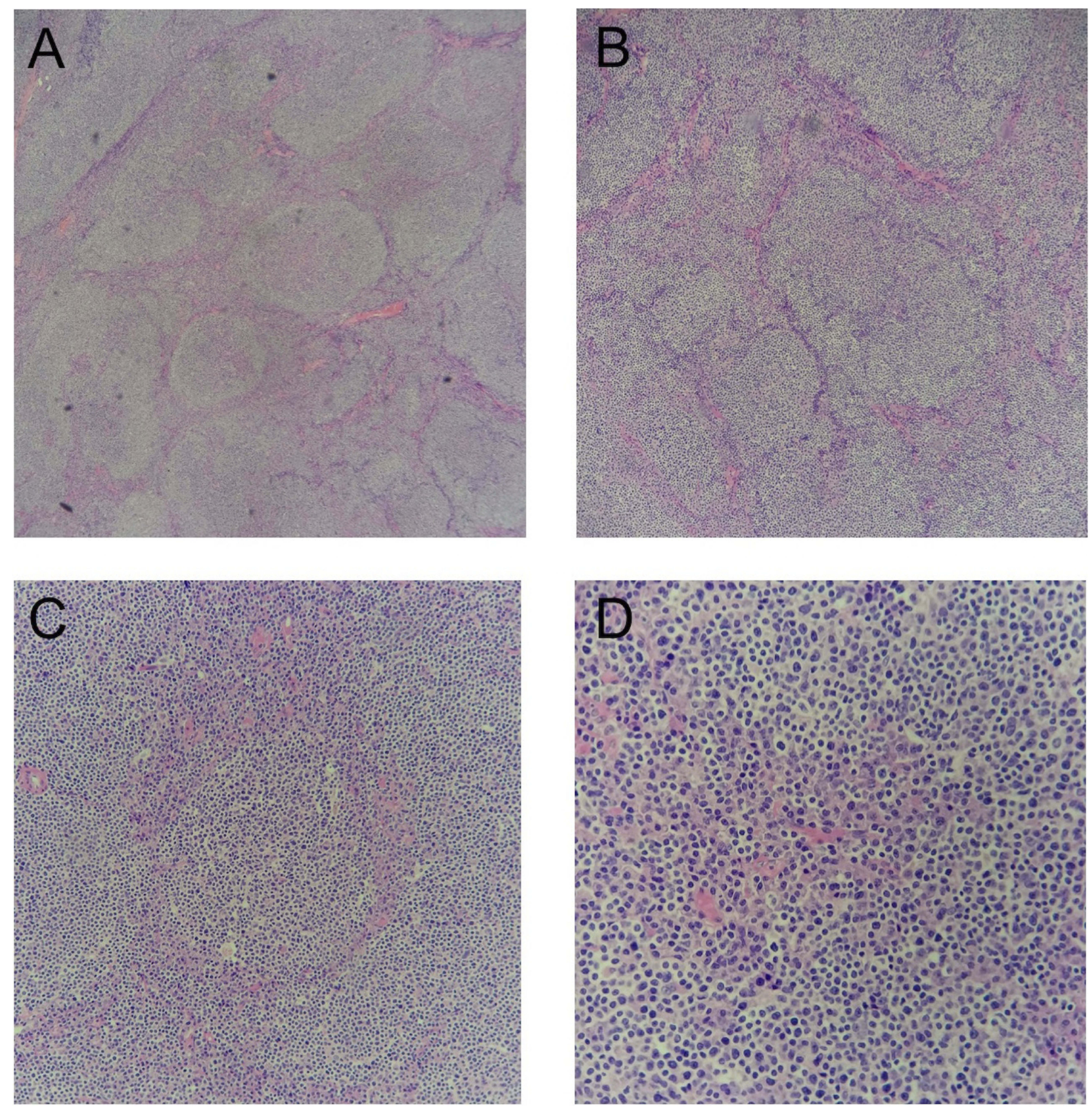

Figure 5 Histopathological sections of the lymph nodes (hematoxylin and eosin staining). Small atypical lymphocytes diffusely or follicle-like distributed and follicle-like structure accounted for $75 \%$ of the whole tissue. The absolute number of centroblasts was $0-5$ for each high-power field. (A) original magnification: $50 \times$; (B) original magnification: 100x; (C) original magnification: 200x; (D) original magnification: 400x.

and MAPK signaling pathways, which are involved in the secretion of various immunoregulatory factors. This process is found in the regulation of both innate and adaptive immune mechanisms. $^{10,11}$

Treon et al identified MYD88 L265P mutation in 91\% of cases with LPL through whole-genome sequencing. ${ }^{5}$ Besides, the mutation is defined as a reliable indicator of diagnosing LPL. Further studies uncovered that MYD88 mutation plays a pivotal role in the pathogenesis, diagnosis, treatment, and prognosis of WM. ${ }^{12-15}$

Recently, the broad application of next-generation sequencing has remarkably increased our knowledge of the molecular and genomic landscape of B-cell lymphomas. Several studies revealed that despite high frequency of mutation in LPL, MYD88 mutation has been found in patients with different B-cell lymphoproliferative diseases, 

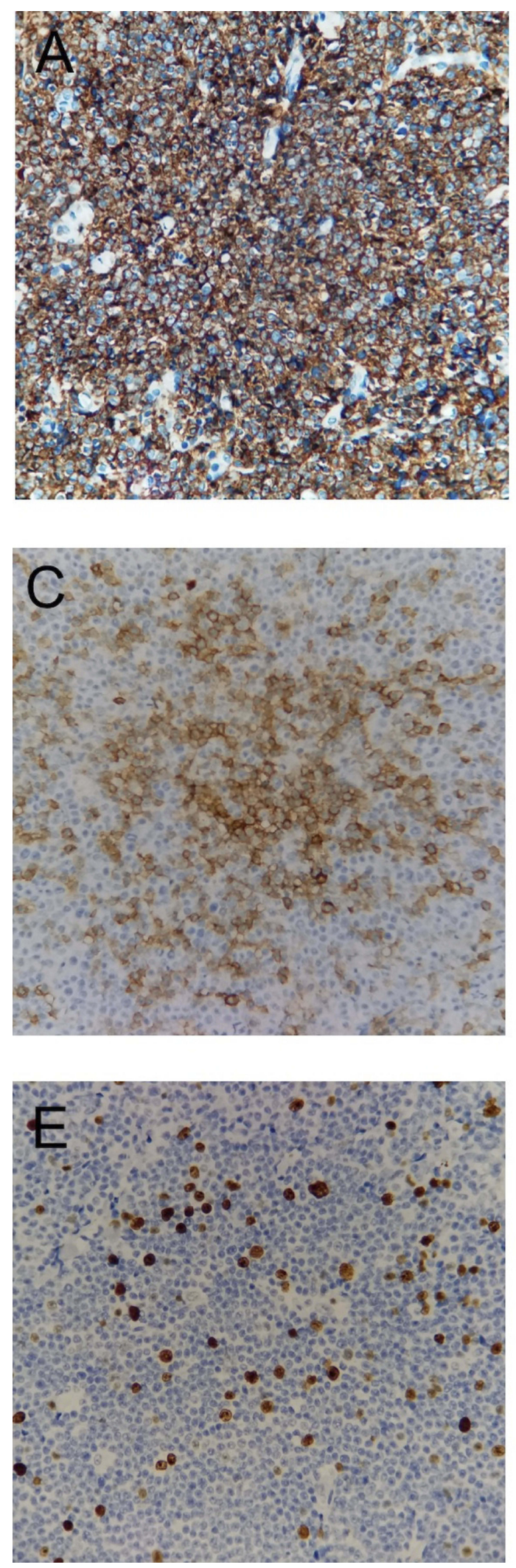
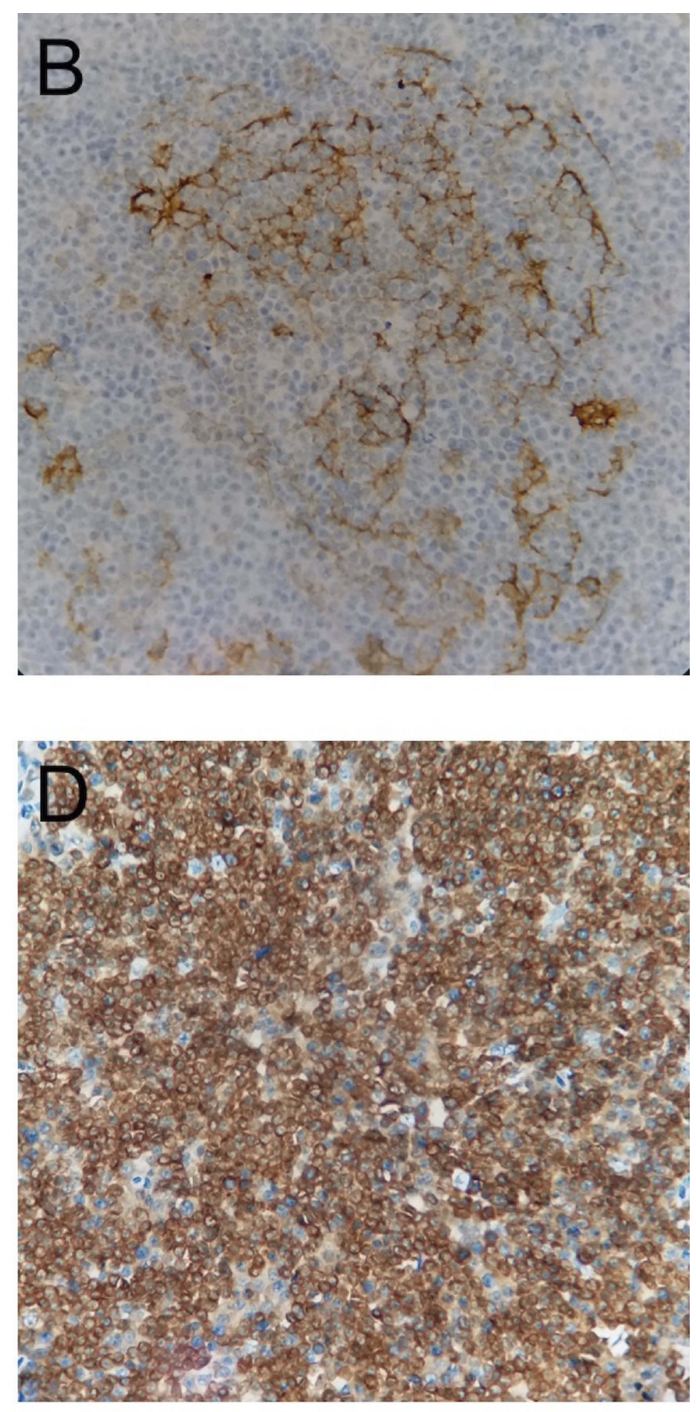

Figure 6 Immunohistochemical staining of the lymph nodes. The tumor cells were positive for (A) CD20 (original magnification: 400x); (B) CD23 (original magnification: 400x); (C) CDI0 (original magnification: 400x); (D) Bcl-2 (original magnification: 400x); (E) Ki-67 (with a proliferation index approximately 5-10\%; original magnification: 400x). The tumor cells were negative for CD3, CD5, and Cycline-DI (data not shown). 
such as immunoglobulin $\mathrm{M}$ monoclonal gammopathy of undetermined significance (IgM-MGUS), nodal marginal zone B-cell lymphoma, chronic lymphocytic leukemia (CLL), diffuse large B-cell lymphoma (DLBCL), and even hairy cell leukemia. ${ }^{6,16,17}$ Bogusz et al reported that the frequency of MYD88 mutation was 3-10\% in CLL/ small lymphocytic lymphoma, 5-7\% in splenic marginal zone lymphoma, and $5 \%$ in nodal marginal zone lymphoma. ${ }^{7}$ Rossi et al integrated mutational and cytogenetic analysis in 1274 CLL samples, and found that MYD88 mutation might be an early molecular event in the clonal evolution of CLL, whereas TP53, SF3B1, and BIRC3 mutations might be late molecular events. ${ }^{18}$ Taken together, MYD88 mutation is of great significance in the pathogenesis of B-cell lymphomas, and also correlates with specific cytogenetic aberrations.

To date, no FL cases with MYD88 mutation have been reported. Okosun et al performed whole-genome or wholeexome sequencing on 10 pairs with the transformation of FL to DLBCL, followed by deep sequencing of 28 genes in an extended cohort. ${ }^{19}$ They reported that the frequency of MYD88 mutation was $0(0 / 100)$ in newly diagnosed FL cases, however, the mutation was found in transformed FL, which differed from that in primary DLBCL. This indicates that MYD88 mutation might be a late molecular event in the clonal evolution of FL. ${ }^{19}$ Oka et al reported a 59-year-old woman presented with high serum total protein, detected on a screening examination. ${ }^{20}$ Laboratory tests revealed high plasma levels of M-protein (IgG- $\lambda$ ), and FDG-PET/CT revealed systemic lymph node swelling and a large tumorous mass in the abdominal cavity. A biopsy of the left supraclavicular lymph node was initially interpreted as LPL. They found that this case was determined to be a type of FL with plasmacytic differentiation based on a positive fluorescent in situ hybridization (FISH) analysis of $\mathrm{IgH}-\mathrm{Bcl} 2$ fusion gene. Our case is similar to the case presented in Oka's report in the context of monoclonal immunoglobulinemia, swollen lymph nodes, and small lymphocytic lymphoma in bone marrow. However, our case has a mutation of MYD88 L265P, and the monoclonal immunoglogulinemia is IgM type. To our knowledge, this is the first report concentrating on FL with monoclonal IgM and MYD88 mutation. The patient poorly responded to RCHOP. Nevertheless, his monoclonal IgM level markedly declined after receiving the bortezomib-based regimen, which NF- $\mathrm{NB}$ signaling pathway might play an important role in the pathogenesis of our case. Previous studies have shown that MYD88 mutation mediates the activation of
NF- $\kappa$ B signaling via both BTK and IRAK pathways. ${ }^{5,15,21}$ We hypothesized that MYD88 L265P mutation might be a main driven factor for the development of FL in our case. Whether the mutation can influence the sensitivity of FL to traditional chemotherapy? Could the mutation be a new target in treating FL? Is FL with MYD88 mutation sensitive to BTK inhibitor, since the latter has a high response rate in MYD88 mutated WM? Answering these questions requires conducting further studies in the future.

\section{Acknowledgments}

We deeply appreciate the kind help provided by pathologist Zhengying Ruan from Taizhou Central Hospital and pathologist Yijian Yu from Taizhou Hospital. This study was funded by grants from Taizhou Science and Technology Bureau (No. 162yw02-5) and Taizhou University (No. 2017PY039).

\section{Disclosure}

The authors report no conflicts of interest in this work.

\section{References}

1. Yang QP, Zhang WY, Yu JB, et al. Subtype distribution of lymphomas in Southwest China: analysis of 6,382 cases using WHO classification in a single institution. Diagn Pathol. 2011;6(1):77. doi:10. 1186/1746-1596-6-77

2. Gross SA, Zhu X, Bao L, et al. A prospective study of 728 cases of non-Hodgkin lymphoma from a single laboratory in Shanghai, China. Int J Hematol. 2008;88(2):165-173. doi:10.1007/s12185-008-0132-1

3. Sun J, Yang Q, Lu Z, et al. Distribution of lymphoid neoplasms in China: analysis of 4,638 cases according to the World Health Organization classification. Am J Clin Pathol. 2012;138(3):429. doi:10.1309/AJCP7YLTQPUSDQ5C

4. Kahl BS, Yang DT. Follicular lymphoma: evolving therapeutic strategies. Blood. 2016;127(17):2055-2063. doi:10.1182/blood-2015-11624288

5. Treon SP, Xu L, Yang G, et al. MYD88 L265P somatic mutation in Waldenström's macroglobulinemia. N Engl J Med. 2012;367(9):826833. doi:10.1056/NEJMoa1200710

6. Jiménez C, Sebastián E, Chillón MC, et al. MYD88 L265P is a marker highly characteristic of, but not restricted to, Waldenstrom's macroglobulinemia. Leukemia. 2013;27(8):1722-1728. doi:10.1038/ leu.2013.62

7. Bogusz AM, Bagg A. Genetic aberrations in small B-cell lymphomas and leukemias: molecular pathology, clinical relevance and therapeutic targets. Leuk Lymphoma. 2016;57(9):1991-2013. doi:10.3109/ 10428194.2016.1173212

8. Oishi N, Kondo T, Nakazawa T, et al. High prevalence of the MYD88 mutation in testicular lymphoma: immunohistochemical and genetic analyses. Pathol Int. 2015;65(10):528-535. doi:10.1111/pin.12336

9. Fontanilles M, Marguet F, Bohers Ã, et al. Non-invasive detection of somatic mutations using next-generation sequencing in primary central nervous system lymphoma. Oncotarget. 2017;8(29):4815748168. doi:10.18632/oncotarget. 18325

10. O'Neill LAJ, Bowie AG. The family of five: TIR-domain-containing adaptors in Toll-like receptor signalling. Nat Rev Immunol. 2007;7 (5):353-364. doi:10.1038/nri2079 
11. Kawai T, Akira S. The role of pattern-recognition receptors in innate immunity: update on Toll-like receptors. Nat Immunol. 2010;11 (5):373-384. doi:10.1038/ni.1863

12. Hunter ZR, Xu L, Yang G, et al. The genomic landscape of Waldenstrom macroglobulinemia is characterized by highly recurring MYD88 and WHIM-like CXCR4 mutations, and small somatic deletions associated with B-cell lymphomagenesis. Blood. 2014;123 (11):1637-1646. doi:10.1182/blood-2013-09-525808

13. Treon SP, Yang C, Lian X, Guang Y, Xia L, Hunter ZR. Somatic mutations in MYD88 and CXCR4 are determinants of clinical presentation and overall survival in Waldenstrom macroglobulinemia. Blood. 2014;123(18):2791-2796. doi:10.1182/blood-2014-01-550905

14. Treon SP, Hunter ZR. A new era for Waldenstrom macroglobulinemia: MYD88 L265P. Blood. 2013;121(22):4434-4436. doi:10.1182/ blood-2013-04-494849

15. Poulain S, Roumier C, Decambron A, et al. MYD88 L265P mutation in Waldenstrom macroglobulinemia. Blood. 2013;121(22):45044511. doi:10.1182/blood-2012-06-436329

16. Ngo VN, Young RM, Schmitz R, et al. Oncogenically active MYD88 mutations in human lymphoma. Nature. 2011;470(7332):115-119. doi:10.1038/nature09671
17. Ondrejka SL, Lin JJ, Warden DW, Durkin L, Cook JR, Hsi ED. MYD88 L265P somatic mutationits usefulness in the differential diagnosis of bone marrow involvement by B-cell lymphoproliferative disorders. Am J Clin Pathol. 2013;140(3):387-394. doi:10.1309/AJCP10ZCLFZGYZIP

18. Davide R, Silvia R, Valeria S, et al. Integrated mutational and cytogenetic analysis identifies new prognostic subgroups in chronic lymphocytic leukemia. Blood. 2013;121(8):1403-1412. doi:10.1182/ blood-2012-09-458265

19. Okosun $\mathrm{J}$, Bodor $\mathrm{C}$, Wang $\mathrm{J}$, et al. Integrated genomic analysis identifies recurrent mutations and evolution patterns driving the initiation and progression of follicular lymphoma. Nat Genet. 2014;46(2):176-181. doi:10.1038/ng.2856

20. Oka T, Kobayashi M, Komori T, et al. Follicular lymphoma with plasmacytic differentiation accompanied by monoclonal IgG gammopathy. Rinsho Ketsueki. 2017;58(6):595-600. doi:10.11406/rinketsu. 58.595

21. Yang G, Xu L, Zhou Y, et al. Participation of BTK in MYD88 signaling in malignant cells expressing the L265P mutation in Waldenstrom's macroglobulinemia, and effect on tumor cells with BTK-inhibitor PCI-32765 in combination with MYD88 pathway inhibitors [abstract]. J Clin Oncol. 2012;30:8106.

\section{Publish your work in this journal}

OncoTargets and Therapy is an international, peer-reviewed, open access journal focusing on the pathological basis of all cancers, potential targets for therapy and treatment protocols employed to improve the management of cancer patients. The journal also focuses on the impact of management programs and new therapeutic agents and protocols on patient perspectives such as quality of life, adherence and satisfaction. The manuscript management system is completely online and includes a very quick and fair peer-review system, which is all easy to use. Visit http://www.dovepress.com/ testimonials.php to read real quotes from published authors. 